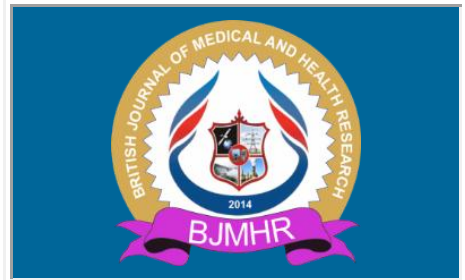

\title{
BJMHR
}

British Journal of Medical and Health Research

Journal home page: www.bjmhr.com

\section{Induced Delusional Disorder: A Case Report}

\author{
P.C.Msoni ${ }^{1}$, A.Tsarkov ${ }^{1,2}$ \& P.Petlovanyi ${ }^{2}$ \\ 1. Chainama Hills College Hospital (CHCH), Lusaka, Zambia \\ 2. Department of Psychiatry, School of Medicine, University of Zambia (UNZA), Lusaka, \\ Zambia
}

\section{ABSTRACT}

Induced Delusional Disorder or Shared Psychosis is a rare psychotic syndrome which involves transference of a delusional belief and or abnormal behaviour from one individual to another or others who has/ have been in close association with the primary affected person. This is a case study of a married couple with five children who had been living on a ten hector plot on a settlement scheme in a district of the Northern Province of Zambia. The wife strongly believed herself to be a prophetess and prophesied that the world would soon come to an end. Over several months she influenced her husband into this belief and together including children started praying and fasting on the isolated farming plot to an extent that children were not allowed to attend school and either couple was not seen at a local market or at the grinding mill. The last born son of about one and half years apparently had developed a fever during this period of isolation. The child was not taken to the health center in the belief that the "Spirit" they had would heal him. The child died five days after the onset of the fever. The death was not reported to authorities in the belief that the body would be resurrected. Relatives and neighbours found the body in a decomposed state two weeks later after forcing their way into the house in which the couple had barricaded itself with the children. Both husband and wife were charged with Murder in a High Court contrary to Section 200 of the Penal Code Chapter 87 the Laws of Zambia. Both husband and wife were admitted at a Forensic Facility for Medical Examinations in terms of Section 17 of the Criminal Procedure Code Chapter 88 of the Laws of Zambia. To the best of our knowledge this is the first documented case of Induced Delusional Disorder from Zambia.

Keywords: Induced Delusional Disorder, Schizophrenia, Forensic Psychiatry, Induced Psychosis

*Corresponding Author Email: anatoliydoc@gmail.com

Received 12 June 2017, Accepted 23 June 2017

Please cite this article as: Msoni et al., Induced Delusional Disorder: A Case Report . British Journal of Medical and Health Research 2018. 


\section{INTRODUCTION}

Induced Delusional Disorder is a rare mental disorder that may occur in two or more individuals who have close emotional contact, but only one of them suffers from a real psychotic disorder. The delusions of this inductor are passed on to other persons who come into contact with and disappear from them when separating with an inductor. Mental illness in a dominant person most often has a schizophrenic nature. Initial obsession with a dominant person and induced delusions are of a chronic nature and in content are often with ideas of persecution, ideas of influence, poisoning or grandeur. Deluded thoughts are transmitted only in special circumstances, when the group has close contacts and is isolated from other languages, culture or geography. Induced Delusional Disorder is found very rarely, but its presence does not exclude this diagnosis. We present the case of a married couple with Induced Delusional Disorder. Treatment issues are discussed, and some reasons for the urgency of early recognition and treatment are explained. To the best of our knowledge this is the first documented case of Induced Delusional Disorder from Zambia.

\section{PRESENTATION ON ADMISSION}

On admission, a wife consistently and persistently claimed that she was a prophetess and that she had acted through the instructions of the spirit at the time of the alleged offence. Specifically, she had been hearing a voice instructing her not to take the sick child to a health center and after death of the child also heard a voice telling her to keep the body of the child and await its resurrection. At interview on admission, she further believed that the world was coming to an end in three months' time hence the need for continued prayer and fasting. On retrospective questioning, she had the belief that she was a prophetess and had the powers of predicting the future over a period of one year before the offence. Significantly on admission, the husband, had already started realizing that not taking the sick child to a health center and not reporting death of the child were not right decisions and felt he should have acted differently.

\section{BACKGROUND INFORMATION ON WIFE}

The wife was a 35-year-old female on admission. She was born normally at home and is said to have had a normal childhood and adolescent development in a rural setting. She started school at seven years and successfully went through Grade VII (Zambian education system) without repeating. For reasons not clearly established, she dropped out in Grade IX. She assisted in household chores at an early age and in early adulthood participated in subsistent farming together with her parents.

It was after leaving school that she joined a Pentecostal Church and gradually rose in the organizational hierarchy to become a leader (Chairperson) in a women's lay group. She has 
ever since been an ardent reader of the Bible upon which she basis her spiritual arguments up till now, often with remarkable accuracy.

At the age of 25 , she got married to a subsistent farmer who did not have much former education and who was easily persuaded into joining her religious beliefs and practices. She had six children whose ages ranged from 1,5 to 15 years from the same man.

She is the third born in a family of 11 siblings all of whom grew up normally into adulthood. The mother is alive and well, but the father died of unknown causes when she was 30-year-old. There is no known history of mental illness in the immediate family. She did not drink alcohol nor smoke cigarettes.

\section{BACKGROUND INFORMATION ON HUSBAND}

The husband was 42-year-old on admission. His early childhood development is rather scanty but it appears that he too had the normal life experiences of growing up in a rural setting. Significantly, he had little formal education having left school at about Grade V level sighting finances as a constraint. He therefore at an early age helped his parents in subsistent farming and later in adulthood with the influence of his wife whom he married at the age of 25, procured a plot in a resettlement farming zone. He was not keen on religious issues before got married. It was his wife, who over the years in their marriage influenced him to assemble with the Pentecostal Church, the church she ardently followed before the marriage. At interview, the husband admitted that the wife had a lot of say in family decisions. In fact, acquisition of the farming plot appears to have been more as a result of the pressure from the wife. He did not drink alcohol nor smoke cigarettes.

\section{FORENSIC HISTORY (FROM DEPOSITIONS OF WITNESSES)}

In the month of March 2012 the Occupation Scheme Manager was approached by relatives of both the husband and the wife requesting for assistance as their children had not been seen going to school. Relatives were further concerned as to how children were thriving as parents were not seen at the market place and at a grinding mill. The relatives were particularly concerned of the health of the children if an intervention was not undertaken.

The Occupation Scheme Manager reported the matter to the District Commissioner who in turn called upon the police officer in-charge of the police station to act accordingly. Police Officers in company of relatives went to the compound where the family lived. The two were found in front of their house. Using a sign language, the visitors were not allowed to go near the house, as they said later, they could contaminate the house with evil spirits. When the police officers insisted that they needed to talk to them the couple got into the house and locked themselves up. The door had to be forced open by the police who found the family in the sitting room. 
On head count, one child, the youngest, was found missing. A search of the house was conducted. A decomposed body of a child wrapped in a cloth was found on a bed in one of the rooms. The body had been kept in that state for about a fortnight.

\section{Warn and Caution Statement (Husband)}

In a WARN and CAUTION STATEMENT at a Police Station, the husband said, "My wife prophesized that the world was coming to an end and advised that we should start serious prayers and fasting. We started telling people who visited us about the prophecy and warned them to start confessing their sins, in preparation for the end of the world. Meanwhile we started the programme of fasting and prayers. It was during this period that we noticed our last born, 18 months of age, unwell. We did not take him to hospital because we believed that the spirit we had was going to heal him. We continued with our fasting and prayers even when our son died five days later. I asked my wife if we should inform other people in the village but my wife refused saying we were in a boat of Noah. We continued with our programme of fasting and prayer. We nevertheless prepared some food for those children who were under age. Relatives started coming at home but we forbade them to come near the house for fear of contaminating the house. They were not like us who were saved by the Lord."

\section{WIFE'S ELDER BROTHER'S DEPOSITIONS OF WITNESSES}

An elder brother to the wife, informed the police that his young sister one day suddenly declared that the second coming of Jesus Christ was very near and warned neighbors to fast and confess. She pointed out that she together with her husband and children had already started fasting and praying. In fact, curiously enough before the prayers and fasting she and her family were observed walking along the perimeter of their plot, in a procession holding candles and rhythmically chanting incantations. The brother later observed that children had stopped going to school and the couple had stopped going to the market place for groceries. The brother got concerned and alerted the neighbors. A group of people in the neighborhood visited the couple's house. Communicating only in a sign language they were not welcome. The couple then got back into the house, locked themselves up and started singing gospel songs. As this behavior appeared abnormal the authorities at the settlement were informed. In order for the police to get access to the couple, the door had to be opened by force.

\section{MENTAL STATUS EXAMINATION ON ADMISSION (WIFE)}

She appeared well kempt, composed and calm but rather reserved, indifferent and remorseless to the charge at hand as she felt it was the right decision to have made. Her speech was normal is flow and tone. She however consistently and persistently claimed that she was a prophetess and admitted hearing a voice especially in the mornings telling her to be strong in character and also often telling her that the world would come to an end three months hence. Orientation 
to time, place and person was not impaired. Her recent and remote memory was however marred by her religious delusions. She maintained that she was a prophetess and justified whatever she had done, felt or thought by referring to passages in the Bible.

\section{MENTAL STATE EXAMINATION ON ADMISSION (HUSBAND)}

Note should be made that the alleged offence was committed ten months before the admission into the Forensic Facility.

On admission, the husband was rather apprehensive of the pending Court appearance. He was remorseful of the events that had happened. At this stage he expressed regret and wished he could have acted differently. His speech was normal in flow and tone with no evidence of thought disorders. He was not deluded. He was well oriented to time, place and person. His memory for recent and remote events was not impaired. He had a good fund of general knowledge and full insight.

\section{DIAGNOSTIC CRITERIA}

The fifth edition of the Diagnostic and Statistical Manual of Mental Disorders (DSM V) outlines five diagnostic criteria in which the diagnosis of Schizophrenia should be made.

\section{Diagnostic Criteria of Schizophrenia 295.90 (F20.9) ${ }^{1}$}

A. Two (or more) of the following, each present for a significant portion of time during a 1 -month period (or less if successfully treated). At least one of these must be (1), (2), or (3):

1. Delusions.

2. Hallucinations.

3. Disorganized speech (e.g., frequent derailment or incoherence).

4. Grossly disorganized or catatonic behavior.

5. Negative symptoms (i.e., diminished emotional expression or avolition).

B. For a significant portion of the time since the onset of the disturbance, level of functioning in one or more major areas, such as work, interpersonal relations, or self-care, is markedly below the level achieved prior to the onset (or when the onset is in childhood or adolescence, there is failure to achieve expected level of interpersonal, academic, or occupational functioning).

C. Continuous signs of the disturbance persist for at least 6 months. This 6 -month period must include at least 1 month of symptoms (or less if successfully treated) that meet Criterion A (i.e., active-phase symptoms) and may include periods of prodromal or residual symptoms. During these prodromal or residual periods, the signs of the disturbance may be manifested by only negative symptoms or by two or more symptoms listed in Criterion A present in an attenuated form (e.g., odd beliefs, unusual perceptual experiences). 
D. Schizoaffective disorder and depressive or bipolar disorder with psychotic features have been ruled out because either 1) no major depressive or manic episodes have occurred concurrently with the active-phase symptoms, or 2) if mood episodes have occurred during active-phase symptoms, they have been present for a minority of the total duration of the active and residual periods of the illness.

E. The disturbance is not attributable to the physiological effects of a substance (e.g., a drug of abuse, a medication) or another medical condition.

F. If there is a history of autism spectrum disorder or a communication disorder of childhood onset, the additional diagnosis of schizophrenia is made only if prominent delusions or hallucinations, in addition to the other required symptoms of schizophrenia, are also present for at least 1 month (or less if successfully treated).

The clinical diagnosis of the wife is Schizophrenia on the basis of presence of delusions and hallucinations (Category A). This is probably the most common diagnosis of the primary case of Induced Delusional Disorder, a diagnosis which the husband retrospectively had at the time of the alleged offence.

Allowing the body of her child to decompose after knowing that the child had died meant that her level of functioning had markedly been impaired as culturally and socially the death should have been reported to relatives and neighbors or relevant authorities (Category B).

The illness had lasted for more than six (6) months (Category C).

Schizoaffective, Depressive Disorder and Bipolar Disorder were excluded through history and Mental State Examination.

History and Physical Examination excluded Drug Abuse and physical conditions both of which can present as Mental Health problems.

\section{DIAGNOSTIC EVALUATION}

The wife (current): Schizophrenia. GAF: 60.

The husband (retrospective - at the time of the alleged offence): Shared Psychotic Disorder (Induced Psychosis). GAF: 55

\section{MANAGEMENT}

The admission to a Forensic Psychiatric Facility for the wife was ordered by the High Court where treatment with Haloperidol and later Risperidone was commenced. Rehabilitation process included individual, group and occupational therapies. Three months after admission she still had positive symptoms and required continued treatment. At this stage a Medical Report in terms of Section $17^{2}$ was formulated. The conclusion was that the wife was laboring under the influence of a Mental Disorder at the time of the alleged offence and that she was not 
fit to make a plea and stand trial. She was then sent back to the High Court where she was sentenced during His Excellency's Pleasure (HEP) and subsequently re-admitted at the Forensic Facility.

Over a period of three years of continued treatment with psychotherapy and antipsychotic medication (oral administration of Risperidone), the wife still believed that she was a prophetess but the intensity of the delusions had decreased and the frequency of hallucinations had reduced. Significantly she began to assert that she would not act on the voices.

She was recommended to be released on presidential pardon about four years after being charged of the offence, on the basis that she had responded well to treatment and had obtained some insight into her illness. It was further felt that she could ably look after her children with supervision. A maintenance dose of an injection of Risperidone (25mg, IM, biweekly) or Zuclopenthixol (200mg, IM, monthly) was recommended to be administered at a local hospital or health center.

The husband was similarly admitted at the Forensic Facility and a Medical Report in Terms of Section 17 was submitted to the High Court. It was pointed out to the Court that at the time of the alleged offence, he had a rare psychiatric phenomenon called Shared Psychotic Disorder (Induced Psychosis). As he was asymptomatic at the time of writing the Report he was deemed fit to stand trial, make a plea and follow proceedings of the Court. He was subsequently acquitted by the Court.

\section{FOLLOW UP}

Two years after the presidential pardon both the wife and the husband were seen at a psychiatric wing of a local hospital. It transpired that the family (mainly brothers and sisters to the wife) had resolved that the couple live with a brother near the provincial headquarters where medication would be easily accessible rather than in resettlement zone. More importantly a family members took charge of the up-keep of the children. Meanwhile the married couple live together on a family plot.

At interview the wife was well kempt, communicable with a normal speech and mien. She played down most of the cardinal symptoms and signs especially that she was aware that she was being interviewed in order to assess the extent of her illness. In that sense she had some insight. The relatives however said she often looked suspicious, irritable and argumentative particularly when discussing biblical issues but got along with her.

The husband was also seen. No overt active psychopathology was elicited. Members of the family said he adequately practiced subsistence farming, related well in the community and from time to time rendered support to his children. 
As pointed out above Induced Delusional Disorder or Shared Psychosis, is a rare psychiatric syndrome which involves transference of a delusional belief and or abnormal behaviors from one individual to another or others, who have been in close associated with the primary affected person. Induced Delusional Disorder is the term used in ICD 10 (F 24) ${ }^{3}$ and shared Psychotic Disorder in DSM V (297.3) ${ }^{1}$.

Pre-requisites for the condition to be established include evidence that partners have been closely associated, have identical content of the delusional system and evidence that partners share, support and accept each other's delusion. Typically, the mentally ill partner has a schizophrenic illness and the "healthy" partner is a spouse, a child or a close relative. Another important factor is that they usually live in social or physical isolation.

Depending on the number of people involved the syndrome is referred to as: folie a' deux, folie a' trois, folie a' quatre, folie a' famille or even folie a' pluisiers.

Various sub-classifications of folie a deux have been proposed to describe how the delusional belief comes to be held by more than one person ${ }^{4-6}$.

Folie imposée in which a dominant person (known as the "primary inducer" or "principal") initially forms a delusional belief during a psychotic episode and imposes it on another person or persons known as "secondary," "acceptor" or "associate".

Folie simultanée where two or more people become psychotic simultaneously and share the same delusion.

Folie communiquée in which there is a contagion of ideas after the "normal" person has resisted them for a long time, but having acquired them maintains them despite separation.

Folie induite where the delusions of one are added to those of another.

The terminology in this disorder has a strong French slant mainly because of the historical background. The syndrome was first conceptualized in the $19^{\text {th }}$ Century French psychiatry by Jean-Pierre Falret and Ernest-Charles Lasègue. Hence the disorder is also known as LasègueFalret syndrome ${ }^{7}$.

Like in most psychiatric disorders hereditary predisposition and environmental factors are crucial in the genesis of this disorder.

\section{ASPECTS OF CRIMINAL OFFENDER AND THE LAW}

Generally, for a Crime to be committed there must be a motive, a plan and implementation of the plan leading to an Act which in turns becomes the Crime. For this process to happen there must be a "Sound Mind" a legal term which implies being aware of the nature of the Act and whether it is right or wrong. Thus criminal culpability for serious offence require ${ }^{8}$ :

1. The Mental State or level of intent to commit a crime, known as the "Mens Rea." 
2. The Act itself associated with committing the offence, known as the "Actus Reus" or "Guilt Act."

3. Concurrence in time between the Guilty Act and the Guilty Mental State.

Mens Rea (The Guilt Mental State) may be affected by some psychiatric conditions which include: paranoid states, manic states, depressive states, delirious states and automatism as seen in seizure disorders.

The McNaughten rule, also commonly known as the right or wrong test, established in the British Courts in 1843 was the precedent for determining legal responsibility ${ }^{9}$. The rule holds that persons are not guilty by reason of insanity if they labored under mental disease such that they are unaware of the nature, the quality and consequences of their acts or if they were incapable of realizing that their acts were wrong.

In 1922 a committee of jurists in England re-examined the McNaughten rule and suggested to broaden the concept of insanity in criminal cases to include the so called "Irresistible Impulse Test" which rules that a person charged with an offence is not responsible for an act if the act were committed under an impulse that a person was unable to resist because of mental illness. This is also called the "Policeman at-the-elbow" Law.

These Rules and Tests have not been satisfactory in making legal decisions upon those with mental illness. Various courts particularly in the United States have tried to redefine the rules. In Durham v U.S. (1954) a decision was made that held that, an accused is not criminally responsible if his unlawful act was the product of mental disease or "mental defect" ${ }^{10}$. These rules and tests are confusing because of the terms used such as "product of mind", "disease" and "defect". There is thus need to sharpen the terminologies and subsequently definitions. A relatively recent rule of for insanity defence was developed by the American Law Institute (ALI Test Law) ${ }^{11}$. The rule states that a defendant is not responsible of criminal conduct where he/she, as a result of mental disease or defect did not possess "substantial capacity either to appreciate the criminality of his conduct or to conform his conduct to the requirements of the law.

Generally, in determining criminal culpability for offences committed by the mentally ill offender, a spectrum of aspects must be considered including cognition, emotion and volition (will).

\section{CONCLUSION}

The association between mental illness and crime is well known. It is the duty of forensic psychiatrist to present to the Courts a clear picture of the psychopathology that may have driven the mentally ill to commit the alleged offence. In turn it is the duty of the Courts to ensure that 
rather than slapping a punitive sentence the mentally ill is sent for treatment and rehabilitation with the aim of subsequent reintegration into the community.

Induced Delusional Disorder is a relatively rare psychotic disorder. It can develop from people who live or have close emotional relationships with mentally ill people, especially with psychotic disorder. Induced delusions can independently, without any treatment, disappear under the condition of their separation or isolation from a mentally ill person, who provoked them the emergence of psychotic symptoms.

Although rare, Induced Psychotic Disorder cases will continue to challenge our understanding of psychiatric phenomenology. In forensic settings, this challenge is multiplied because psychiatric experts must be able to explain this complex disorder to the judge who is most often non-medically trained people.

\section{REFERENCES}

1. Diagnostic and Statistical Manual of Mental Disorders: Fifth Edition (DSM-V ${ }^{\mathrm{TM}}$ ). American Psychiatric Association. 2013. P. 87-123.

2. Section 17 of the Criminal Procedure Code Chapter 88 of the Laws of Zambia. The Criminal Procedure Code Act. Available at http://www.parliament.gov.zm/sites/default/files/documents/acts/Criminal\%20Proced ure\%20Code\%20Act.pdf (Accessed on $22^{\text {th }}$ January, 2018).

3. The ICD-10 Classification of Mental and Behavioural Disorders: Clinical Descriptions and Diagnostic Guidelines (1st Edition). World Health Organization; 1 edition (January 1, 1992). pp. 104-105.

4. Sims A. An Introduction to Descriptive Psychopathology. 2 nd ed. WB Saunders; 1955.

5. Dewhurst, Kenneth; Todd, John (1956). "The psychosis of association: Folie à deux". Journal of Nervous and Mental Disease. 124: 451-459. doi:10.1097/00005053195611000-00003.

6. Gralnick, A. (1942). Folie a deux-the psychosis of association. The Psychiatric Quarterly. 16(3): 491-520.

7. C. Lasègue, J. Falret: La folie à deux ou folie communiquée. Annales medicopsychologiques, Paris, 1877, 18: 321-355.

8. Asokan, T. V. (2016). The insanity defense: Related issues. Indian J Psychiatry. 58(2): S191-S198.

9. Asokan TV. Daniel McNaughton (1813-1865) Indian J Psychiatry. 2007;49: 223-4.

10. Durham v. United States, 214 F.2d 862 (D.C. Cir. 1954). JUSTIA US Law. Available at https://law.justia.com/cases/federal/appellate-courts/F2/214/862/314341/ (Accessed $26^{\text {th }}$ January, 2018). 
11. ALI Test Law and Legal Definition. USLegal. Available at https://definitions.uslegal.com/a/a-1-i-test/ (Accessed 26 ${ }^{\text {th }}$ January, 2018).

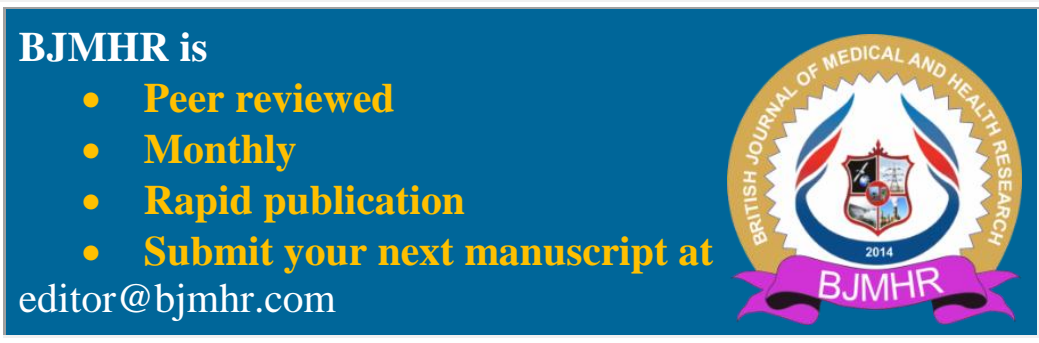

